\title{
A modified infarct exclusion technique: Triple-patch technique for postinfarction ventricular septal perforation
}

\author{
Tsutomu Sugimoto, MD, Shinpei Yoshii, MD, PhD, Kazuo Yamamoto, MD, PhD, Kenji Sakakibara, MD, PhD, \\ Yasunori lida, MD, PhD, Akifumi Uehara, MD, Takehito Mishima, MD, and Sigetaka Kasuya, MD, PhD, Nagaoka, Japan
}

$\mathrm{P}$ ostinfarction ventricular septal perforation (VSP) remains an important complication of myocardial infarction. The prevalence is approximately $1 \%$ to $2 \%$ among patients with acute myocardial infarction, and it is often fatal unless surgical treatment is performed. Despite numerous improvements in surgical technique, the mortality remains about $19 \%$ to $40 \%{ }^{1}$ Perioperative low-output syndrome and residual shunt are associated with a poor outcome. We operated on 4 patients with our simple technique that minimizes residual shunting.

\section{Materials and Methods}

Operative Technique. Cardiopulmonary bypass was established, and myocardial revascularization if necessary was performed on the beating heart before repair of the VSP. The heart was then arrested with a cardioplegic solution, and repair was done through a longitudinal left ventriculotomy in the infarcted area, about 1 to $2 \mathrm{~cm}$ away from the left anterior descending coronary artery. First, a tailored small bovine pericardial patch was used to close the VSP directly with a running 3-0 polypropylene suture. Then two bovine pericardial patches were cut into rectangular shapes. One pericardial patch was sutured to the noninfarcted endocardium around the ventricular septal side, and the other patch was sutured to the noninfarcted endocardium of the anterolateral ventricular wall, both with running 3-0 polypropylene sutures. These two patches were then cut and sewn to determine the ideal size and shape of the pouch fitting the left ventricular cavity to make an infarct exclusion. After the VSP patch and endoventricular pouch were sutured, fibrin glue was applied to fill the cavity between the patches. The ventriculotomy was closed in two layers with two polytetrafluoroethylene felt strips and 2-0 polypropylene sutures (Figure 1).

PAtiEnTs. Between 1996 and 2006, a total of 10 patients underwent VSP repair. Through 2003, we performed VSP repair by the David-Komeda method in 6 patients. Since 2004, the new triplepatch technique has been used for all patients.

\footnotetext{
From the Department of Cardiovascular Surgery, Tachikawa Medical Center, Nagaoka, Japan.

Received for publication Aug 14, 2007; accepted for publication Nov 8 , 2007.

Address for reprints: Tsutomu Sugimoto, MD, Department of Cardiovascular Surgery, Tachikawa Medical Center, 3-2-11, Kanda-Machi, Nagaoka, Niigata, 940-8621, Japan (E-mail: tsugimoto-cvs@umin.ac.jp).

J Thorac Cardiovasc Surg 2008;135:702-3

$0022-5223 / \$ 34.00$

Copyright $\odot 2008$ by The American Association for Thoracic Surgery doi:10.1016/j.jtcvs.2007.11.034
}

Statistical Analysis. Preoperative and postoperative variables were compared between the two operative groups with the Mann-Whitney $U$ test.

\begin{abstract}
Results
With this procedure, anterior VSPs were repaired in 3 patients and a posterior VSP was repaired in 1 patient. Concomitant coronary artery bypass grafting was performed in 2 patients. There was 1 operative death of low cardiac output in a patient with repair of an anterior VSP. The incidence of postoperative residual shunt was greater in the David-Komeda group than in the new triple-patch technique group (Table 1).
\end{abstract}

\section{Discussion}

David and associates ${ }^{2}$ and Komeda and colleagues ${ }^{3}$ reported the possibility of reconstructing the left ventricle with single-patch repair. This technique improved surgical mortality, because the endocardial patch could be placed to exclude infarcted myocardium and maintain ventricular geometry. Between 1996 and 2003, we performed VSP repair by the David-Komeda infarction exclusion method. Although there were no operative deaths, postoperative residual shunt was common (in $50 \%$ of cases, pulmonary/systemic blood flow ratio was $>2.0$ ). One patient with recurrence of VSP underwent a second operation. One disadvantage of this method is the difficulty in suturing the pouch to the myocardium, because it is necessary to determine the size and shape of the pericardial pouch beforehand. Subsequently, some modified techniques for the infarction exclusion method have been devised to prevent postoperative residual shunt. $^{4,5}$

We modified the David-Komeda infarction exclusion method to use three patches. Our surgical technique has some advantages. First, a small patch of bovine pericardium is used to close the VSP directly, and the cavity between the small patch and pouch can be sealed with fibrin glue. This avoids excessive tension on the fragile ventricular septum and prevents residual shunt formation. Second, by closing the two bovine pericardial patches after suturing in the intact myocardium, we can easily adjust the ideal size and shape of the endocardial pouch. Four patients in our series underwent VSP repair with this method, and there was no significant residual shunt in any case.

Repair of posterior VSP is associated with higher perioperative mortality than that of anterior VSP. Mitral dysfunction may occur as a result of derangement of ventricular geometry or papillary muscle damage from myocardial infarction or surgical injury. In our limited experience, by making an incision in the inferior wall of the left ventricle $10 \mathrm{~mm}$ from the posterior descending artery, we can use this simple technique for patients with posterior VSP without causing damage to the papillary muscle. In conclusion, in our limited experience this modification to the infarct exclusion technique appears to reduce operative mortality and recurrence of VSP. 

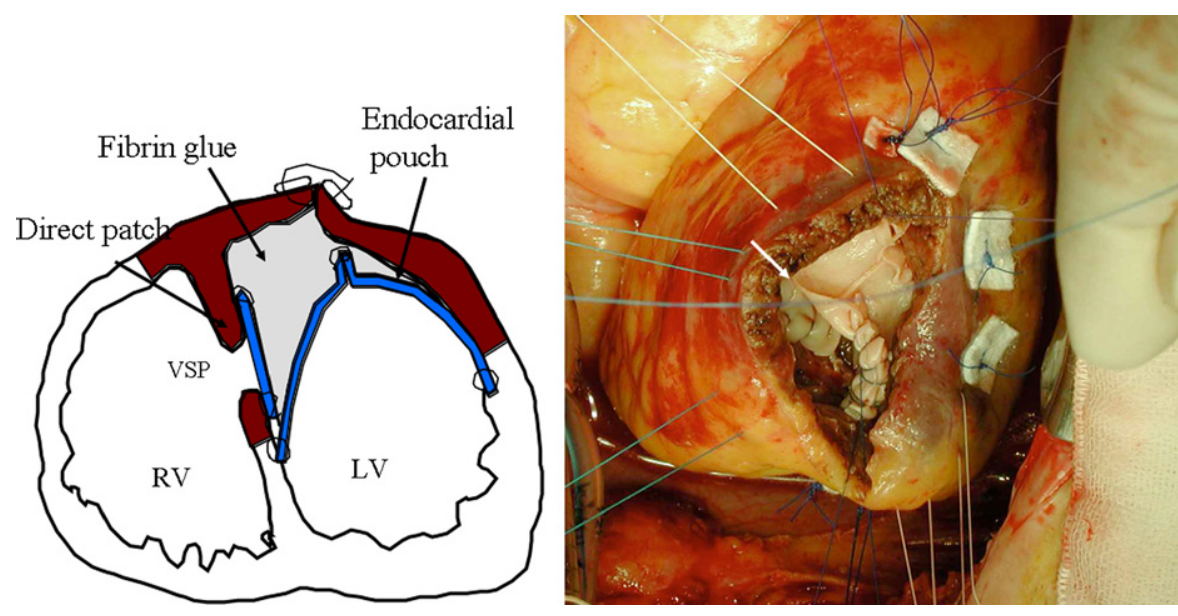

Figure 1. Intraoperative photographs of repair of postinfarction ventricular septal perforation (VSP). Initial bovine patch was sutured around ventricular septal perforation. Next, two bovine pericardial patches that were fixed to noninfarcted endocardium around ventricular septum and anterolateral wall were then cut and sewn to determine final size and shape of pouch fitting left ventricular (LV) cavity. RV, Right ventricle.

TABLE 1. Clinical results of $\mathbf{1 0}$ patients who underwent ventricular septal perforation repair

\begin{tabular}{|c|c|c|c|c|c|c|c|c|c|}
\hline \multirow[b]{2}{*}{ Age (y) } & \multirow[b]{2}{*}{ Sex } & \multirow[b]{2}{*}{ VSP } & \multirow{2}{*}{$\begin{array}{c}\text { Preop cardiac } \\
\text { support }\end{array}$} & \multirow{2}{*}{$\begin{array}{c}\text { Operation } \\
\text { (number of distal } \\
\text { anastomoses) }\end{array}$} & \multirow[b]{2}{*}{ Op time (min) } & \multirow[b]{2}{*}{ Clamp time (min) } & \multicolumn{2}{|c|}{ Q̀p/Q்s } & \multirow[b]{2}{*}{ Result } \\
\hline & & & & & & & Preop & Postop & \\
\hline \multicolumn{10}{|l|}{$2001-2003$} \\
\hline 81 & M & Ant & IABP & $\begin{array}{c}\text { David-Komeda }+ \\
\text { CABG (1) }\end{array}$ & 305 & 119 & 4.7 & 2.1 & Alive \\
\hline 75 & $\mathrm{~F}$ & Ant & IABP & David-Komeda & 210 & 88 & 4.1 & 1.3 & Alive \\
\hline 64 & M & Ant & IABP & $\begin{array}{c}\text { David-Komeda }+ \\
\text { CABG (1) }\end{array}$ & 330 & 128 & 2.5 & 1.1 & Alive \\
\hline 71 & $\mathrm{~F}$ & Ant & None & $\begin{array}{c}\text { David-Komeda + } \\
\text { CABG (1) }\end{array}$ & 274 & 122 & 5.3 & 1.3 & Alive \\
\hline 67 & $\mathrm{~F}$ & Post & None & David-Komeda & 345 & 150 & 4.4 & 2.0 & Alive \\
\hline $\begin{array}{c}76 \\
\text { Mean } \pm \text { SD } \\
72.3 \pm 6.3 \\
2004 \text { onward }\end{array}$ & $\mathrm{F}$ & Ant & IABP & David-Komeda & $\begin{array}{c}475 \\
323.2 \pm 88.5\end{array}$ & $\begin{array}{c}163 \\
128.3 \pm 26.2\end{array}$ & $\begin{array}{c}2.8 \\
3.9 \pm 1.1\end{array}$ & $\begin{array}{c}2.7 \\
1.7 \pm 0.6\end{array}$ & Alive \\
\hline $\begin{array}{l}2004 \text { onward } \\
77\end{array}$ & $\mathrm{~F}$ & Post & IABP & 3-patch + CABG (2) & 317 & 120 & 4.2 & 1.1 & Alive \\
\hline 74 & M & Ant & IABP & 3-patch + CABG (1) & 510 & 149 & 2.5 & 1.1 & Dead \\
\hline 81 & $\mathrm{M}$ & Ant & $\mathrm{IABP}$ & 3-patch + TAP & 252 & 101 & 1.8 & 1.5 & Alive \\
\hline $\begin{array}{l}71 \\
\text { Mean } \pm \text { SD } \\
\quad 75.8 \pm 3.7\end{array}$ & $\mathrm{M}$ & Ant & $I A B P+P C P S$ & 3-patch & $\begin{array}{c}240 \\
329.8 \pm 108.0\end{array}$ & $\begin{array}{c}89 \\
114.8 \pm 22.7\end{array}$ & $\begin{array}{c}3.3 \\
2.9 \pm 1.0\end{array}$ & $\begin{array}{c}1.0 \\
1.2 \pm 0.2^{*}\end{array}$ & Alive \\
\hline
\end{tabular}

$\dot{\mathrm{Q} p} / \dot{\mathrm{Q}} s$, Pulmonary/systemic blood flow ratio; VSP, ventricular septal perforation; Preop, preoperative; Op, Operative; Postop, Postoperative; $M$, male; $A n t$, anterior; IABP, intra-aortic balloon pump; $C A B G$, coronary artery bypass grafting; F, female; Post, posterior; 3-patch, triple-patch repair; TAP, tricuspid annuloplasty; $P C P S$, percutaneous cardiopulmonary support. ${ }^{*} P<.05$.

\section{References}

1. Deja MA, Szostek J, Widenka K, Szafron B, Spyt TJ, Hickey MJ, et al. Post infarction ventricular septal defect—can we do better? Eur J Cardiothorac Surg. 2000;18:194-201.

2. David TE, Dale L, Sun Z. Postinfarction ventricular septal rupture: repair by endocardial patch with infarct exclusion. $J$ Thorac Cardiovasc Surg. 1995;110:1315-22.
3. Komeda M, Fremas SE, David TE. Surgical repair of postinfarction ventricular septal defect. Circulation. 1990;82(5 Suppl):IV243-7.

4. Shibata T, Suehiro S, Ishikawa T, Hattori K, Kinoshita H. Repair of postinfarction ventricular septal defect with joined endocardial patches. Ann Thorac Surg. 1997;63:1165-7.

5. Tabuchi N, Tanaka H, Arai H, Mizuno T, Nakahara H, Oshima N, et al. Double-patch technique for postinfarction ventricular septal perforation. Ann Thorac Surg. 2004;77:342-3. 